\title{
Flow cytometry for rapid detection of Salmonella spp. in seed sprouts
}

\author{
Bledar Bisha ${ }^{1}$, and Byron F. Brehm-Stecher ${ }^{2 *}$ \\ ${ }^{1}$ Department of Animal Science, University of Wyoming, Laramie, WY, USA \\ ${ }^{2}$ Department of Food Science and Human Nutrition, Rapid Microbial Detection and Control Laboratory, lowa State \\ University, Ames, IA, USA \\ *Corresponding author's e-mail address: byron@iastate.edu
}

Published online: 31 December 2014 (version 1)

Cite as: Bisha B. and Brehm-Stecher B.F., ScienceOpen Research 2014 (DOI: 10.14293/S2199-1006.1.SOR-LIFE.AJ19WR.v1)

Reviewing status: Please note that this article is under continuous review. For the current reviewing status and the latest referee's comments please click here or scan the QR code at the end of this article.

Primary discipline: Life sciences

Keywords: Salmonella, Seed sprouts, Rapid detection, Fluorescence In Situ Hybridization (FISH), Flow Cytometry

\begin{abstract}
Seed sprouts (alfalfa, mung bean, radish, etc.) have been implicated in several recent national and international outbreaks of salmonellosis. Conditions used for sprouting are also conducive to the growth of Salmonella. As a result, this pathogen can quickly grow to very high cell densities during sprouting without any detectable organoleptic impact. Seed sprouts typically also support heavy growth $\left(\sim 10^{8} \mathrm{CFU} \mathrm{g}^{-1}\right)$ of a heterogeneous microbiota consisting of various bacterial, yeast, and mold species, often dominated by non-pathogenic members of the family Enterobacteriaceae. This heavy background may present challenges to the detection of Salmonella, especially if this pathogen is present in relatively low numbers. We combined DNA-based fluorescence in situ hybridization (FISH) with flow cytometry (FCM) for the rapid molecular detection of Salmonella enterica ser. Typhimurium in artificially contaminated alfalfa and other seed sprouts. Components of the assay included a set of cooperatively binding probes, a chemical blocking treatment intended to reduce non-specific background, and sample concentration via tangential flow filtration (TFF). We were able to detect $S$. Typhimurium in sprout wash at levels as low as $10^{3} \mathrm{CFU} \mathrm{ml}{ }^{-1}$ sprout wash $\left(10^{4} \mathrm{CFU} \mathrm{g}{ }^{-1}\right.$ sprouts $)$ against high microbial backgrounds $\left(\sim 10^{8} \quad\right.$ CFU $\mathrm{g}^{-1}$ sprouts $)$. Hybridization times were typically $30 \mathrm{~min}$, with additional washing, but we ultimately found that $S$. Typhimurium could be readily detected using hybridization times as short as 2 min, without a wash step. These results clearly demonstrate the potential of combined DNA-FISH and FCM for rapid detection of Salmonella in this challenging food matrix and provide industry with a useful tool for compliance with sprout production standards proposed in the Food Safety Modernization Act (FSMA).
\end{abstract}

\section{INTRODUCTION}

Although they are regarded as a healthy food from a nutritional standpoint [1, 2], seed sprouts (alfalfa, broccoli, radish, mung bean, etc.) have historically been problematic from a food safety perspective, as they have been associated with several multistate and international outbreaks of bacterial disease over the past decade or longer [3, 4]. Pathogens involved in these outbreaks have included Salmonella, Escherichia coli 0157:H7, Bacillus cereus, and Yersinia enterocolitica $[5,6]$. The most common pairing has been Salmonella in alfalfa sprouts. The high incidence of Salmonella contamination of alfalfa sprouts may be rooted in ecological factors, such as the capacity of this pathogen to adhere strongly to sprout surfaces so that it is retained at high levels in the finished product, even after periodic irrigation during the sprouting process $[7,8]$. Over the years, various serovars of $S$. enterica have been involved in sprout-borne outbreaks, including Bareilly, Cubana, Enteritidis, Kottbus, Mbandaka, Muenchen, Newport, Saintpaul, Stanley, Weltevreden and others $[9,10,11,12]$. Despite the availability of long-standing regulatory guidance on best practices for safe production of sprouts [13], outbreaks of salmonellosis due to consumption of contaminated seed sprouts continue to be a chronic food safety problem $[3,9,12,14]$. As of this writing (December, 2014), an outbreak involving Salmonella Enteritidis linked to mung bean sprouts is ongoing, with 111 people in 12 states infected (http://www.cdc.gov/salmonella/outbreaks-2014. html).

Development of improved seed sanitation treatments as a means to increase sprout safety has been an area of intense effort in the past few years [3, 15]. However, no treatment yet developed has been able to completely eliminate Salmonella or other pathogens from seeds [11, 15]. The warm, aqueous, nutrient-rich conditions used to sprout the seeds provide an excellent environment for microbial growth $[5,6,7,16]$. Remarkably, the doubling time for an $S$. enterica strain growing on germinating alfalfa seeds has been found to approach that observed for the same strain growing in LB broth, a nutritionally rich medium [16]. It is therefore not uncommon for contaminated sprouts to contain final levels of 
Salmonella of up to $10^{7} \mathrm{CFU} \mathrm{g}^{-1}[10,11]$. Given the inherent difficulties in effective sampling so that contaminated seed is not used for production of sprouts, or in decontamination of seeds so that Salmonella does not multiply to hazardous levels during the sprouting process, different tactics are needed to help increase the safety of seed sprouts. Increased product testing of sprouts or spent irrigation water (SIW) has therefore been advocated as an important means for increasing the safety of commercially produced sprouts $[13,17]$. In this study, we sought to develop a simple and streamlined method for rapid presence/absence detection of whole Salmonella cells directly in seed sprouts. Our approach combines the specificity of whole cell molecular staining of Salmonella via fluorescence in situ hybridization (FISH) with the capacity of flow cytometry (FCM) to detect labeled cells within complex and heterogeneous mixtures of cells and particulate matter. We developed optimal probe combinations and hybridization conditions, applied a chemical blocking treatment for reduction of non-specific probe binding, evaluated sample concentration via tangential flow filtration (TFF), and explored the rapidity of our hybridization protocol. Together, these procedures form the basis of a rapid, simple, and direct assay for detection of Salmonella cells in this physically and microbiologically complex food matrix. In light of recent multistate outbreaks of Salmonella in sprouts, and considering the recurring nature of such outbreaks, our study has direct relevance to public health and safety.

\section{MATERIALS AND METHODS}

Reagents and growth media

Denhardt's solution $(50 \times$ concentrate $)$ and ExoSAP-IT enzyme mixture were from USB Corporation (Cleveland, $\mathrm{OH}$ ). Microbiological media were from Difco Laboratories, Inc. (Detroit, MI). Unless otherwise mentioned, all other materials were from Sigma-Aldrich (St Louis, MO).

\section{Bacterial strains and culture conditions}

Salmonella enterica subsp. enterica ser. Typhimurium ATCC 14028 and E. coli ATCC 25922 (negative control culture) were from the American Type Culture Collection (ATCC, Manassas, VA). Seven Salmonella strains representing each of the seven DNA subgroups within this genus were from the Salmonella Genetic Stock Centre (SGSC, University of Calgary, Canada; http://salmonella.bio.ucalgary.ca/). These strains were used to verify the performance and species coverage of probes or their combinations under the conditions used here. These strains included $S$. enterica subsp. enterica ser. Typhimurium SA3250 (DNA subgroup I), S. enterica subsp. salamae SA4406 (DNA subgroup II), subsp. arizonae SA4407 (DNA subgroup IIIa), subsp. diarizonae SA4408 (DNA subgroup IIIb), subsp. houtenae SA4409 (DNA subgroup IV), subsp. indica SA4411 (DNA subgroup VI), and S. bongori SA4410 (DNA subgroup V, formerly $S$. brookfield). All cultures were inoculated from plate or broth stocks stored at $4^{\circ} \mathrm{C}$ and were grown in Trypticase Soy Broth (TSB) at $30^{\circ} \mathrm{C}$ for $20-22$ hours prior to use.

\section{Cell harvesting and fixation}

Cells of $S$. Typhimurium were harvested via centrifugation and washed once in $0.1 \%$ peptone water to remove residual medium prior to being spiked into sprout samples. Strains used for studies on probe specificity and subspecies coverage were pelleted without an initial wash, fixed for $30 \mathrm{~min}$ with $10 \%$ buffered formalin, re-suspended in a 50:50 mixture of absolute ethanol/RNase-free distilled water, and stored at $20^{\circ} \mathrm{C}$ until used.

\section{Oligonucleotide probes}

Four oligonucleotide probes targeting the 23s rRNA of Salmonella spp. were identified from either the scientific or patent literature $[18,19,20,21,22]$ and evaluated for use in cytometric detection of Salmonella spp., individually and in combination. The names (both common and systematic) and sequences of the Salmonella-specific DNA probes evaluated in this study are given in Table 1. Probes (Integrated DNA Technologies, Coralville, IA) were synthesized with a 5'-Cy5 modification and purified by HPLC. Probes were

Table 1. Names, sequences and reported specificities of probes used in this study.

\begin{tabular}{|c|c|c|c|c|}
\hline Probe name & Systematic name ${ }^{a}$ & Sequence $\left(5^{\prime}\right.$ to $\left.3^{\prime}\right)$ & Reported specificity & References \\
\hline 1200 & L-S-Sal-0340-a-A-28 & AGC TCA CAG CAT ATG CGC TTT TGT GTA C & $\begin{array}{l}353 \text { of } 366 \text { Salmonella strains detected; test strains } \\
\text { not listed by DNA subgroup; S. bongori not detected }\end{array}$ & [20] \\
\hline Sa1 & L-S-Sal-0345-a-A-20 & ACA GCA CAT GCG CTT TTG TG & $\begin{array}{l}\text { S. enterica belonging to DNA subgroups I, IIla (not all } \\
\text { strains), IIIb, IV, VI }\end{array}$ & {$[18,22]$} \\
\hline Sal3 & L-S-Sal-1713-a-A-18 & AAT CAC TTC ACC TAC GTG & $\begin{array}{l}\text { S. enterica belonging to DNA subgroups I, II, IIIb, } \\
\mathrm{IV}, \mathrm{VI}\end{array}$ & {$[18,21]$} \\
\hline Salm-63 & L-G-Sal-1742-a-A-18 & TCG ACT GAC TTC AGC TCC & $\begin{array}{l}\text { S. enterica belonging to DNA subgroups I, II, IIIa, IIIb, } \\
\mathrm{IV} \text {, VI; S. bongori (DNA subgroup V); Plesiomonas } \\
\text { shigelloides }\end{array}$ & [19] \\
\hline
\end{tabular}

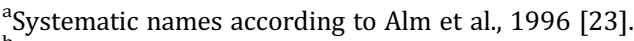

${ }^{\mathrm{b}}$ Theoretical cross-hybridization (in silico result) with two additional sequences in the SILVA 23S rRNA database also recently reported for Salm$63[24]$. 
re-suspended to a working concentration of $500 \mathrm{ng} \mu \mathrm{l}^{-1}$ in nuclease-free low-TE buffer (10 mM Tris-HCl [pH 8.0], $0.1 \mathrm{mM}$ EDTA), aliquoted into polypropylene microcentrifuge tubes (to minimize freeze-thaw of a single bulk master stock), and stored at $-20^{\circ} \mathrm{C}$ until used.

\section{Determination of optimal hybridization conditions and evaluation of probe combinations}

Salmonella-targeted probes described in the scientific or patent literature (Table 1) were tested both alone and in combination against either S. Typhimurium ATCC 14028 or the seven SGSC strains representative of the seven DNA subgroups that comprise the genus Salmonella (I, II, IIIa, IIIb, IV, $\mathrm{V}$, and VI). E. coli ATCC 25922 was used as a negative control to examine the degree of non-specific binding. To determine optimal hybridization conditions using $S$. Typhimurium ATCC 14028, we held hybridization time constant at $30 \mathrm{~min}$ and examined various probe concentrations ranging from 5 to $10 \mathrm{ng} \mathrm{l}^{-1}$, salt concentrations ranging from $0.5 \mathrm{M}$ to $1.0 \mathrm{M}$ $\mathrm{NaCl}$ and hybridization temperatures ranging from $45^{\circ} \mathrm{C}$ to $55^{\circ} \mathrm{C}$. In an effort to maximize separation of stained target cells from the sample background and to ensure the broadest coverage possible of the genus Salmonella, combinations or "cocktails" of one or more probes were also examined. The brightest probe cocktail was evaluated for inclusivity against the seven-strain SGSC set.

\section{Cooperative binding of Sal3 and Salm-63}

Based on initial data from probe combinations, we sought to explore the possibility of cooperative binding effects between Sal3 and Salm-63. To do this, we hybridized $S$. Typhimurium with either Salm-63-Cy5 alone ( $30 \mathrm{~min}, 55^{\circ} \mathrm{C}, 5 \mathrm{ng} / \mu \mathrm{l}$ probe) or with Salm-63-Cy5 combined with an unlabeled version of Sal3 (30 min, $55^{\circ} \mathrm{C}, 2.5 \mathrm{ng} / \mu \mathrm{l}$ each probe). Both hybridizations were carried out using $0.7 \mathrm{M} \mathrm{NaCl}$. All appropriate controls including hybridization of the same probe concentrations and combinations against E. coli were also performed. Differences between treatments were quantified via FCM after hybridization.

\section{Seed sprouts}

Retail sprouts (alfalfa, broccoli, and radish, from a single Midwestern producer) were obtained from a local grocery store and used within 2 days of purchase.

\section{Cultural and molecular characterization of endogenous sprout microbiota}

An initial qualitative molecular survey of the cultivable microbes from commercially purchased sprouts was performed in conjunction with cultural characterization via plating. Briefly, sprout samples were serially diluted in $0.1 \%$ peptone water, plated on Trypticase Soy agar (TSA, for bacteria) or Dichloran Rose Bengal Chloramphenicol agar (DRBC, for yeasts and molds), and incubated at $30^{\circ} \mathrm{C}$ for $24 \mathrm{~h}$ (TSA) or $25^{\circ} \mathrm{C}$ for $72 \mathrm{~h}$, in the dark (DRBC). From each set of plates, several colonies were selected on the basis of colony morphology, with attempts made to select unique colony types. However, because many different types of bacteria may exhibit similar colony morphologies, we sampled a number of bacterial colonies displaying a "generic" (small, white, opaque) morphology. Total nucleic acids were isolated from bacterial or yeast colonies using PrepMan Ultra sample preparation reagent (Applied Biosystems, Foster City, CA), according to the manufacturer's instructions. For bacterial colonies, a portion of each resulting crude template was used in a polymerase chain reaction (PCR) with the primers DA71 and DA72 [25]. For yeasts and molds, two sets of primers (ITS1/ITS4 and F63/R635) were used in separate reactions [26]. The PCRs used a commercial master mix (Eppendorf 2.5x MasterMix), and cycling conditions were followed as originally described for each set of primers $[25,26]$. Successful amplification was verified via gel electrophoresis and excess primers, and dNTPs were removed prior to cycle sequencing using a commercial mixture of exonuclease I and shrimp alkaline phosphatase (ExoSAP-IT, USB Corporation, Cleveland, OH). Cycle sequencing was performed at the Iowa State University's DNA Facility (http://www.dna.iastate.edu), using the forward primers for each reaction. Sequences were uploaded into 4Peaks sequence viewing software (v. 1.7.2; http://mekentosj.com/ 4peaks) and compared against the GenBank database using the BLAST program (National Center for Biotechnology Information; http://www.ncbi.nlm.nih.gov). Isolates were identified to the genus level on the basis of similarity to GenBank sequences (98-100\% similarity typically observed).

\section{Scanning electron microscopy of alfalfa sprout samples}

The physical and microbiological complexity of alfalfa sprout samples was documented using scanning electron microscopy (SEM) as described previously [27]. Briefly, $25 \mathrm{~g}$ of fresh, unadulterated retail sprouts were homogenized in $225 \mathrm{ml}$ $0.1 \% \mathrm{PW}$, and $1 \mathrm{ml}$ portions of the homogenate were removed and pelleted $(2000 \times g, 5 \mathrm{~min})$. The supernatant was discarded and samples were fixed for $15 \mathrm{~min}$ in $2.5 \%$ EM-grade glutaraldehyde. After fixation, samples were re-suspended in PBS and shipped to the University of Iowa's Central Microscopy Research Facility (CMRF) for analysis. At CMRF, a drop of the fixed sample was applied to a poly-Llysine-treated silicon chip, allowed to adhere for $5 \mathrm{~min}$, then samples were fixed further in 1\% osmium tetroxide, followed by dehydration in an ethanol series, sputter coating and viewing via SEM using an Hitachi S-3400N microscope.

\section{Artificial contamination of sprout samples}

Prior to use in experiments, sprouts were serially diluted in $0.1 \%$ peptone water and examined culturally for the presence 
of Salmonella by plating onto Xylose Lysine Tergitol 4 (XLT-4) agar, with incubation for $24 \mathrm{~h}$ at $35^{\circ} \mathrm{C}$. Total aerobic counts were obtained by plating onto TSA, with incubation at $30^{\circ} \mathrm{C}$ for 24 hours. Salmonella-spiked sprouts were prepared by aseptically placing $25 \mathrm{~g}$ sprouts in a sterile Stomacher filter bag, followed by the addition of between $10^{3}$ and $10^{7} \mathrm{CFU}$ $\mathrm{g}^{-1}$ S. Typhimurium ATCC 14028 , depending on the experiment. Inocula were left in contact with the sprouts for $\sim 2$ hours at room temperature and spiked sprouts were aseptically placed in another Stomacher filter bag, diluted 10-fold with $225 \mathrm{ml} 0.1 \%$ peptone water, and the mixture stomached for $1 \mathrm{~min}$ at $230 \mathrm{rpm}$ in a reciprocating paddle-type sample homogenizer (Stomacher Circulator 400, Seward Ltd., Norfolk, UK). Serial dilutions were performed in $0.1 \%$ peptone water followed by plating onto XLT-4 agar and incubating as above. Colonies were counted and expressed as colony forming units (CFU) per gram of sprouts.

\section{Pre-analytical sample preparation}

After stomaching, sprout samples were prepared for hybridization as follows: fresh sprout homogenate was vacuum filtered through four layers of sterile cheesecloth to remove large (visible) sprout particulates. Individual samples $(1.3 \mathrm{ml})$ were aliquoted into in $1.5 \mathrm{ml}$ polypropylene microcentrifuge tubes and centrifuged briefly at low speed $(30 \mathrm{~s}, 300 \times g)$ to remove any remaining visible sprout particulates. One milliliter of the supernatant was transferred to a fresh tube, and cells (both endogenous sprout microbiota and Salmonella) were pelleted via centrifugation $(5 \mathrm{~min}, 2000 \times g$ ). The supernatant was gently poured off and the samples were fixed for $30 \mathrm{~min}$ at ambient temperature $\left(\sim 25^{\circ} \mathrm{C}\right)$ by adding one volume $(1 \mathrm{ml})$ of $10 \%$ buffered formalin (Sigma-Aldrich, St. Louis, M0). After fixation, samples were pelleted (5 min, $2000 \times g$ ), the supernatant was discarded and sample pellets were re-suspended in a 50:50 mixture of absolute ethanol/ RNase-free distilled water and stored until use at $-20^{\circ} \mathrm{C}$. Samples prepared in this manner could be stored indefinitely, with no apparent impact on rRNA probe staining profile or other sample properties. It is important to note that prior to transfer of pelleted cells from one liquid system to another (e.g. from sprout wash to fixative or from fixative to storage buffer), it was important to first re-suspend the pellet in a minimal, residual portion $(\sim 20 \mu \mathrm{l})$ of the outgoing liquid system. This prevented clumping, resulting in suspensions of individual cells suitable for cytometric analysis. In some samples, treatment with Denhardt's solution [28] was investigated as a means for blocking nonspecific binding of FISH probes to endogenous sprout microbiota or particulate matter. Initial experiments suggested the use of Denhardt's solution at a $5 \times$ concentration (a 1:10 dilution of the commercially available $50 \times$ stock solution), yielding a final concentration of $0.1 \%$ for each of the components of this mixture (acetylated bovine serum albumin, Ficoll and polyvinylpyrrolidone-90). The addition of $5 \times$ Denhardt's solution was examined at three separate points: prior to fixation (with subsequent removal before addition of formalin), during fixation, or during hybridization. The most effective point for addition for Denhardt's solution as a background suppressant was determined using FISH and FCM against Salmonellacontaminated sprout samples.

Another pre-analytical preparative step, TFF, was investigated as a means for increasing detection sensitivity. For this procedure, sprout samples were first diluted $1: 10$ in $0.1 \%$ peptone water and homogenized in a Stomacher blender as mentioned earlier. After the initial cheesecloth filtration step, sprout homogenate was concentrated up to 30 -fold within 10-25 min using a bench scale TFF instrument equipped with a $0.2 \mu \mathrm{m}$ filter (Labscale TFF/Pellicon XL 50 filter cassette, Millipore Corporation, Billerica, MA). Following concentration, samples were fixed and re-suspended in cell storage buffer as described in "Cell harvesting and fixation" section. Some samples were concentrated even further after the TFF step by simple centrifugation $(2000 \times g, 5 \mathrm{~min})$, followed by re-suspension of pelleted material in cell storage buffer at one-tenth of their initial volume.

\section{Time course hybridization of Salmonella ser. Typhimurium in alfalfa sprouts}

Here we examined the speed with which $S$. Typhimurium could be resolved from non-target microbes and sprout particulate matter via combined FISH and FCM. Sprouts were inoculated at approximately $10^{6} \mathrm{CFU} \mathrm{g}^{-1}$ with $S$. Typhimurium and processed for hybridization as described earlier, including treatment with Denhardt's solution (added $30 \mathrm{~min}$ prior to fixation). Samples were hybridized with the dual probe cocktail (Sal3-Cy5 and Salm-63-Cy5, each probe at $2.5 \mathrm{ng} \mu^{-1}$ ) for $0,2,4,6,15,20$, or $30 \mathrm{~min}$. At each time point, the hybridization reaction was stopped with a 10 -fold dilution in hybridization buffer not containing probe. Diluted samples were placed on ice until further processing (pelleting and re-suspension of cells in Phosphate Buffered Saline, PBS), then examined via FCM. For the time zero treatment, the sample was diluted immediately after addition of probe to the pre-heated sample.

\section{FCM and data analysis}

Samples (pure cultures and sprouts) were examined with a FACSCanto flow cytometer (BD Biosystems, San Jose, CA) using a $647 \mathrm{~nm}$ (red) laser for Cy5 excitation. Briefly, hybridized samples were resuspended in $1 \mathrm{ml}$ PBS and run at either a low flow rate $\left(10 \mu \mathrm{lmin}^{-1}\right)$ collecting 5000-50,000 events depending on the experiment or high flow rate $(120 \mu \mathrm{l}$ $\min ^{-1}$ ) for up to 3 minutes. The choice of flow rate was dependent on the level of Salmonella contamination. A high flow rate was chosen to increase throughput (decrease run times) for samples inoculated with low levels of Salmonella. 
Data were analyzed using FlowJo software (version 8.8.6, Tree Star, Inc., Ashland, OR).

\section{RESULTS}

\section{Establishment of optimal hybridization conditions and evaluation of probe combinations}

Variables affecting probe-binding behavior and subsequent hybridization brightness include hybridization time and temperature, probe concentration, and salt concentration. Probes may also interact with each other (directly or indirectly) when used in combination. With a 30 min hybridization time held constant, we tested various probe concentrations ranging from 5 to $10 \mathrm{ng}^{-1} \mathrm{l}^{-1}$, salt concentrations ranging from $0.5 \mathrm{M}$ to $1.0 \mathrm{M} \mathrm{NaCl}$, hybridization temperatures ranging from 45 to $55^{\circ} \mathrm{C}$ and various combinations of the probes listed in Table 1 . We quickly established that a concentration of $5 \mathrm{ng}$ $\mu^{-1}$ probe and hybridization at $55^{\circ} \mathrm{C}$ for 30 min yielded acceptable results for all probes, confirming prior work done with Sal3 alone [29]. Sal1 and Salm-63 responded unexpectedly to differing salt concentrations. For example, at $1 \mathrm{M} \mathrm{NaCl}$, Sal1 was the brightest probe, with a geometric mean signal intensity (GMSI) of 172, followed by Sal3 (GMSI 156), 1200 (GMSI 110) and Salm-63 (GMSI 74.4). However, under the more stringent conditions of $0.7 \mathrm{M} \mathrm{NaCl}$, Salm-63 was the brightest probe (GMSI 143), followed by Sal3 (GMSI 133), 1200 (GMSI 113) and Sal1 (GMSI 64.7). Although overall probe brightness was typically higher with $1 \mathrm{M} \mathrm{NaCl}$, staining was more uniform and populations were more focused when $0.7 \mathrm{M} \mathrm{NaCl}$ was used (data not shown). Therefore, $0.7 \mathrm{M} \mathrm{NaCl}$ was used in all subsequent experiments.

When probe combinations were examined, we generally found that use of more than one probe did not lead to sizeable increases in fluorescence over single-probe hybridizations [30]. However, one exception was with the combination of Sal3 and Salm-63. When these two probes were combined, a greater than expected increase in signal intensity was observed. This result suggested the possibility of cooperative binding interactions between these two probes, and was examined further as described below.

\section{Cooperative binding of Sal3 and Salm-63 and verification of cocktail inclusivity}

The potential for cooperative binding activities between Sal3 and Salm-63 as the basis for the unexpectedly large signal increase seen when these two probes were used together was investigated. This was done by combining Salm-63-Cy5 with an unlabeled version of Sal3 and hybridizing as described in Materials and Methods. Our results clearly indicate that the unlabeled Sal3 exerted a cooperative "helper" [31] effect on the binding of Salm-63-Cy5, resulting in an increase in fluorescence for this probe, as illustrated in Figure 1. Although we did not examine these interactions further, we assume that these effects are reciprocal and that similar increases in

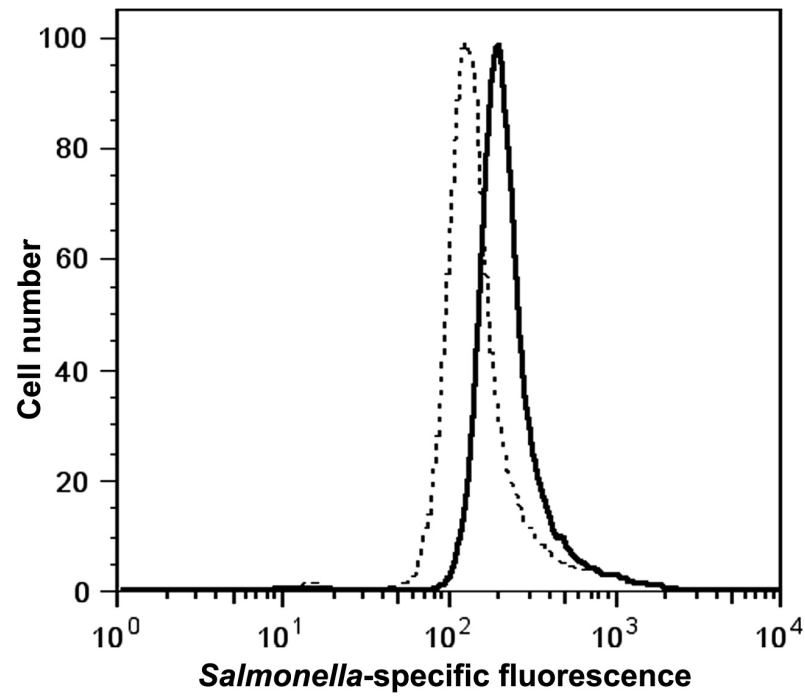

Figure 1. Cooperative binding of probes Sal3 and Salm-63. From our cytometric screening of multi-probe cocktails, we observed that the combination of Sal3 and Salm-63 was unexpectedly bright. Noting the physical proximity of the binding sites (Sal3: $E$. coli positions 1713-1730; Salm-63: E. coli positions 1742-1760), we hypothesized that these two probes might be binding cooperatively via "helper"-type interactions known to open the structure of the ribosome, providing greater physical access to binding sites (23). To test this hypothesis, we compared the signal intensity for cells of $S$. Typhimurium SA3250 stained with Salm-63-Cy5 alone (dotted histogram, GMSI = 153) with those labeled using a combination of Salm-63-Cy5 and unlabeled Sal3 (bold histogram, GMSI = 225). These results confirmed our hypothesis, indicating that the unlabeled Sal3 acted as a "helper" probe, the binding of which enhanced the signal intensity of Salm-63-Cy5. Although we did not perform the reciprocal experiment (staining with a cocktail of Sal3-Cy5 and an unlabeled Salm-63), we assume that these probes exhibit mutually interactive binding in the fully labeled dual probe cocktail used to label Salmonella in alfalfa sprouts.

fluorescence would be seen if Sal3-Cy5 were combined with an unlabeled Salm-63 "helper".

Because we used Sal3 and Salm-63 under different conditions than originally reported for either probe $[19,21]$, we also sought to experimentally verify the reactivity of these probes toward Salmonella spp. under the new conditions used here. This was done by hybridizing these probes, alone or in combination, against a Salmonella strain set representative of the 7 DNA subgroups belonging to this genus (SGSC strains, Materials and Methods). Under the hybridization conditions used here, both probes yielded the same subgroup coverage as originally reported [19] (Table 1). Briefly, Sal3 hybridized with strains representative of all subgroups except IIIa and V. Sal3 staining of the subgroup IV strain, although positive, was weaker than other positive reactions with this probe. Salm-63 
stained Salmonella belonging to all 7 Salmonella DNA subgroups. The Sal3/Salm-63 cocktail also stained strains from all 7 DNA subgroups, but with the increased fluorescence intensity characteristic of this cooperatively binding probe pair. The only exception to this observation was with S. arizonae (subgroup IIIa), staining of which was no brighter than with Salm-63 alone against this organism.

\section{Cultural and molecular characterization of endogenous sprout microbiota}

Plating experiments indicated that the microbiological quality and character of the sprout samples we used in this work were typical of this food, as reported previously [3, 32, 33, $34,35]$. Specifically, mesophilic plate counts for three separate packages of retail alfalfa sprouts sampled over a period of 4 months ranged from $3.7 \times 10^{8}$ to $7.3 \times 10^{8} \mathrm{CFU} \mathrm{g}^{-1}$ sprouts. Plate counts for two separate packages of retail broccoli or radish sprouts sampled over a period of 2.5 months ranged from 6.3 to $6.6 \times 10^{8} \mathrm{CFU} \mathrm{g}^{-1}$ (broccoli) and 4.5 to $7.3 \times 10^{8} \mathrm{CFU} \mathrm{g}^{-1}$ (radish). Yeasts and molds from DRBC plates were typically in the range of $10^{5}$ to $10^{6} \mathrm{CFU} \mathrm{g}^{-1}$. To explore these samples further, we performed a simple molecular survey of endogenous sprout microbiota after plating onto TSA and DRBC, as described in Materials and Methods. A total of 18 bacterial colonies (9 from alfalfa sprouts, 5 from broccoli sprouts and 4 from radish sprouts) and 4 yeast colony types (all from alfalfa) were examined via PCR and partial rRNA gene sequencing. In order to perform this qualitative molecular survey of cultivable sprout microbiota, we first sought out unique colony types for both bacteria and yeast. Because different types of bacteria may share a generic colony type (small, white, opaque), we sampled a number of colonies having this morphology. Therefore, this survey was only qualitative and may not reflect the true prevalence of each microbial type present in the sprout samples. BLAST searches of the resulting sequences indicated that Pseudomonas spp. were the most frequent bacterial isolates. These were present in all sprout types and five Pseudomonas isolates were also recovered from DRBC plates. Most identifications were made to the genus level, but one alfalfa sample yielded a clear identification as $P$. viridiflava, a plant pathogen belonging to the P. syringae group. Pantoea/Enterobacter spp. were also isolated from sprouts (alfalfa and radish). The four fungal isolates from alfalfa were identified as either Cryptococcus macerans or Penicillium spp.

\section{Scanning electron microscopy (SEM) of alfalfa sprouts}

Figures 2 and 3 (and Figure 4, described in the section below) highlight the microbial and physical complexity of the alfalfa sprout matrix. Figure 2 shows the dense assemblage of rod-shaped cells characteristic of the native bacterial load present on alfalfa and the other seed sprouts we worked with, including broccoli and radish. Panel A shows a layer of bacterial cells covering a sprout surface. Panel B shows similar cell types embedded in the extracellular matrix of a sprout surface biofilm. Figure 3 shows the types and range of particulate matter we typically found in sprout matrices,
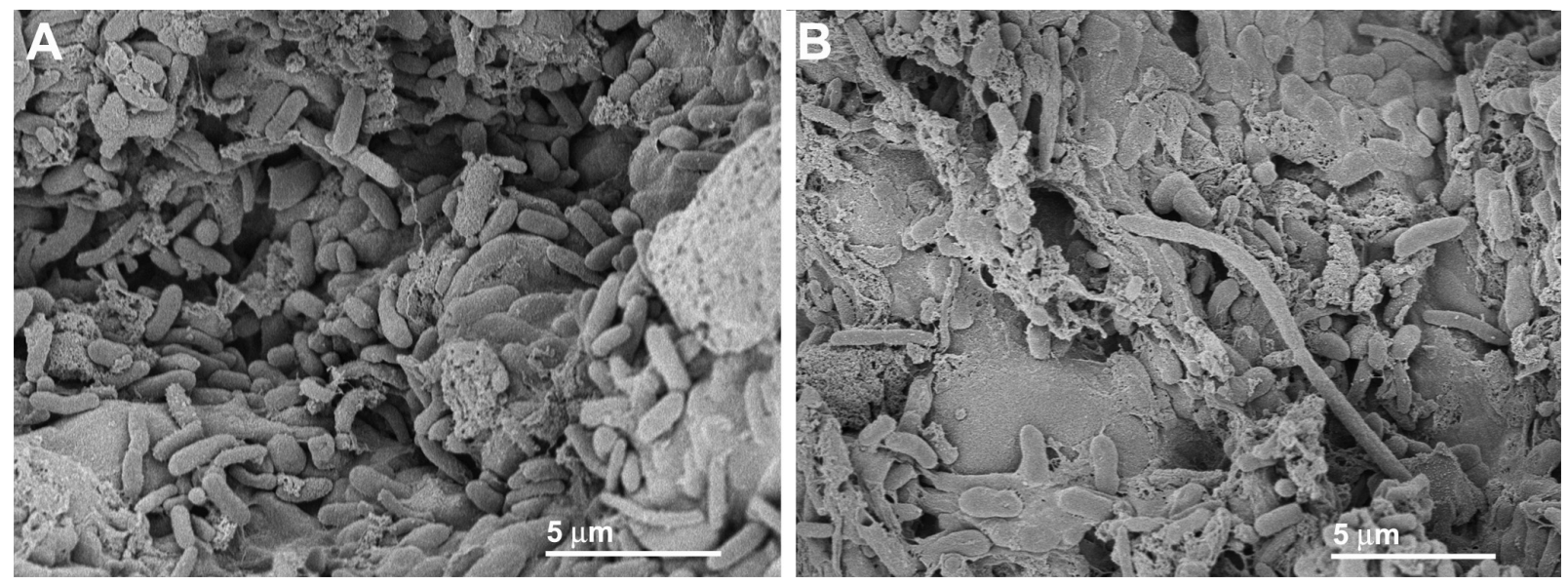

Figure 2. Scanning Electron Microscopy (SEM) of native sprout microbiota and biofilm. We performed SEM to investigate the microbial complexity of retail alfalfa sprouts. These photos confirm the presence of large numbers of rod-shaped bacteria that are physically indistinguishable from typical Salmonella cells. Panel A: loosely attached assemblage of endogenous sprout bacteria; Panel B: native sprout biofilm, with cells embedded in an extracellular matrix. While it is doubtful that the presence of these biofilms impacted our detection of Salmonella cells spiked into alfalfa sprouts, it is possible that in naturally contaminated sprouts, Salmonella spp. may also participate in biofilm formation. Cells that are buried within biofilm structures, or firmly attached to particulate matter may be more difficult to detach and detect. Therefore, it would also be valuable to examine our approach using seeds inoculated with Salmonella spp. prior to sprouting, more closely simulating naturally contaminated samples. (Panel B adapted from reference [36] with permission from APHA Press, the copyright holder.) 


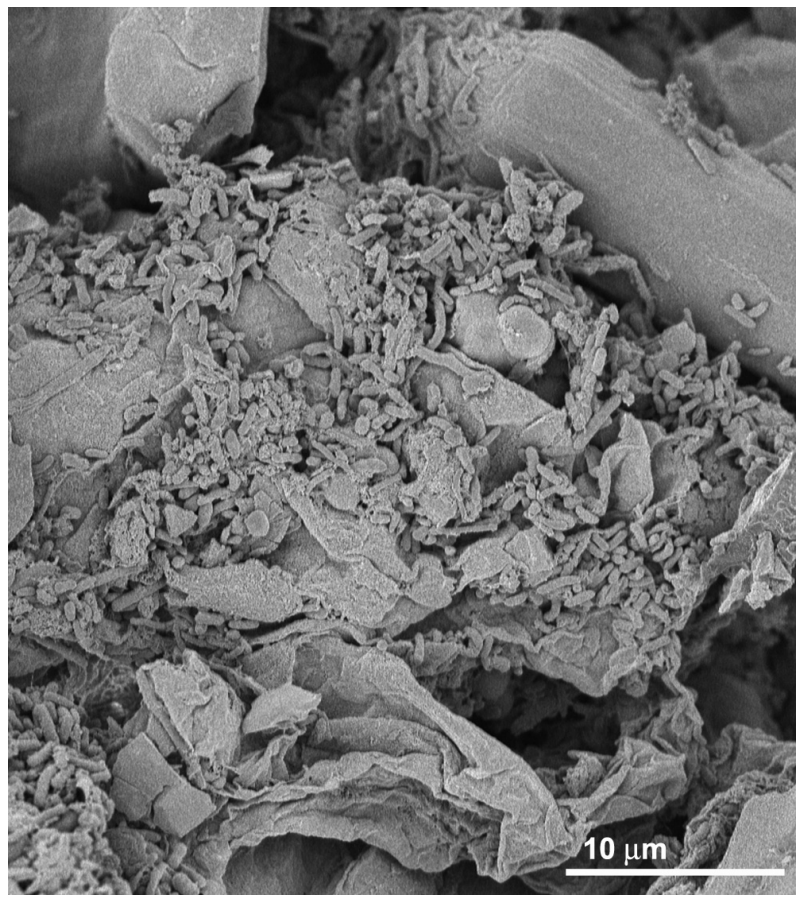

Figure 3. Scanning Electron Microscopy (SEM) of native sprout microbiota attached to sprout particulate matter. SEM results illustrate the physical complexity of alfalfa sprout samples, showing the presence of large sprout particulates with native bacteria attached. These include a palisade parenchyma cell (large columnar structure at upper right) and a "deflated" root or stem structure (bottom center).

including palisade parenchyma cells (large columnar structure, upper right hand corner) and stems, roots or the debris from these (collapsed tubular structure, bottom center).

\section{Effects of physical and chemical pre-analytical sample preparation}

As noted in Materials and Methods, we examined physical approaches (filtration and centrifugation) for pre-analytical sample preparation in efforts to enhance detection of $S$. Typhimurium in sprouts. Specifically, after stomaching, sprout homogenates were vacuum filtered through four layers of sterile cheesecloth to remove visible sprout particulates, such as stems and leaves. Samples were then centrifuged briefly at low speed $(30 \mathrm{~s}, 300 \times g)$ to remove any additional macroparticulates. These quick and simple preparative steps were used to avoid fouling of additional preparative (TFF) or analytical (FCM) instruments. Although these treatments did remove visible debris, Figure 4 demonstrates that they did not minimize the physical complexity of this food matrix at the microscopic level.

Denhardt's solution, a polymeric mixture commonly used for blocking nucleic acid membrane surfaces, was also investigated as a chemical treatment for suppressing background fluorescence due to non-specific binding of probes to the surfaces of non-target microbiota or sprout particulates. Preliminary experiments identified $5 \times$ Denhardt's solution as an effective usage level. Use of Denhardt's at this level was examined at three separate points in the sample preparation flow: prior to fixation (with subsequent removal before addition of formalin), during fixation and during hybridization. Results from cytometry indicated that addition of $5 \times$ Denhardt's prior to fixation suppressed background signal and enhanced Salmonella-specific staining (data not shown). Therefore, this was used as a default treatment to lower the nonspecific staining in many, but not all subsequent experiments. However, we found that while Denhardt's treatment was effective, it was not critical to assay performance, and
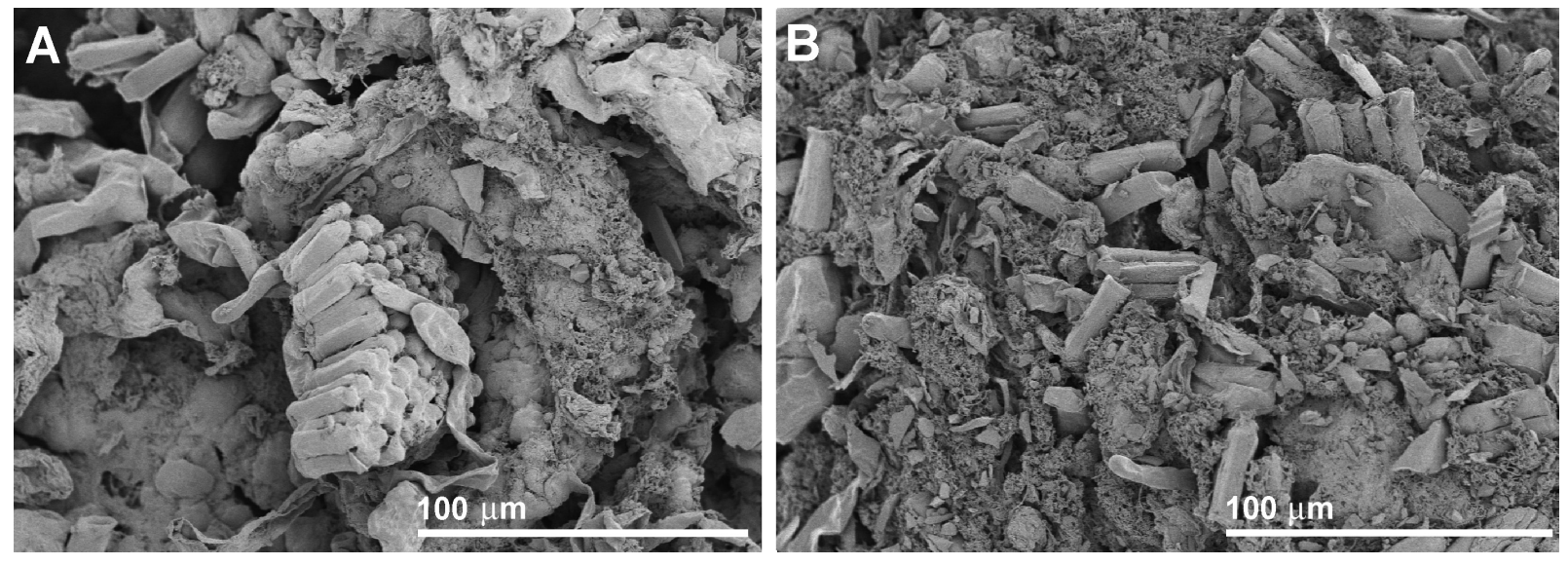

Figure 4. Treatment of alfalfa sprout samples with cheesecloth filtration and low-speed centrifugation does not impact physical complexity at the microscopic level. These lower-magnification SEM photos of an untreated sample (Panel A) or a sample treated with cheesecloth and centrifugation (Panel B) shows that both samples have a similar physical complexity at the microscopic level, and contain relatively large pieces of plant debris (stem or root material) and palisade parenchyma cells, all coated with a fine, fuzzy network of native sprout bacteria. 
Salmonella subpopulations could be detected without its use (Figure 6, below).

\section{Time course labeling of Salmonella ser. Typhimurium in alfalfa sprouts}

We also examined probe-conferred brightness of $S$. Typhimurium in sprouts as a function of time. Figure 5, panel $\mathrm{A}$ is a plot of the Geometric Mean Signal Intensity (GMSI) of the Salmonella subpopulation $\left(10^{6} \mathrm{CFU} S\right.$. Typhimurium/g sprouts) over time $(0,2,4,6,1520$ and $30 \mathrm{~min})$. Near-maximal staining occurred after only 15 min hybridization. Panel $B$ is a composite dot plot from the same dataset, comprised of results from four treatments: $0,2,4$ and $15 \mathrm{~min}$, labeled as populations a, b, c and d, respectively. Although the populations increased in definition over time as staining equilibrated and became more uniform, $S$. Typhimurium was clearly distinguishable from the sprout background (population a) after as little as 2 min hybridization (population b). Using the same elliptical gate (re-centered at each timepoint to accommodate rightward shifts in probe-conferred fluorescence), the number of events in each $S$. Typhimurium subpopulation was found to be essentially the same at each timepoint. Specifically, with each separate cytometry file consisting of approximately 32,000 events, the number of events falling within the gated $S$. Typhimurium subpopulation at each time point ranged between 185 and 215 (mean event number of 194.83; standard deviation 10.93). These data indicate that the equivalent number of $S$. Typhimurium cells were detected at each time point, clearly demonstrating the ability of our assay to rapidly resolve $S$. Typhimurium from within this complex food matrix with as little as 2 min hybridization and without the need for a subsequent wash step.

\section{Impact of TTF on detection sensitivity}

To explore whether it could enhance our limit of detection, some samples were concentrated further using TFF, with or without additional centrifugal concentration (of endogenous cells, Salmonella and sprout particulates) from TFF permeates. The results are shown in Figure 6. Without TFF, the detection limit of our assay was $10^{5}$ CFU Salmonella $\mathrm{g}^{-1}$ sprout $\left(10^{4} \mathrm{CFU} \mathrm{ml} \mathrm{m}^{-1}\right.$ sprout wash). Without concentration, putatitve Salmonella subpopulations could be discerned at inoculum levels of $10^{4} \mathrm{CFU}$ Salmonella $\mathrm{g}^{-1}$ sprout $\left(10^{3} \mathrm{CFU}\right.$ $\mathrm{ml}^{-1}$ sprout wash; circular highlight, Panel A), but reliable visual determination at this level was not possible. However, with a 10-fold TFF-based concentration of this sample (Panel B), or a combination of TFF with additional centrifugal concentration of the permeate (effectively a 100 -fold concentration of the original sample, Panel C), $S$. Typhimurium could be clearly and reliably detected by eye at $10^{4} \mathrm{CFU}$ Salmonella $\mathrm{g}^{-1}$ sprouts $\left(10^{3} \mathrm{CFU} \mathrm{ml}{ }^{-1}\right.$ sprout wash).
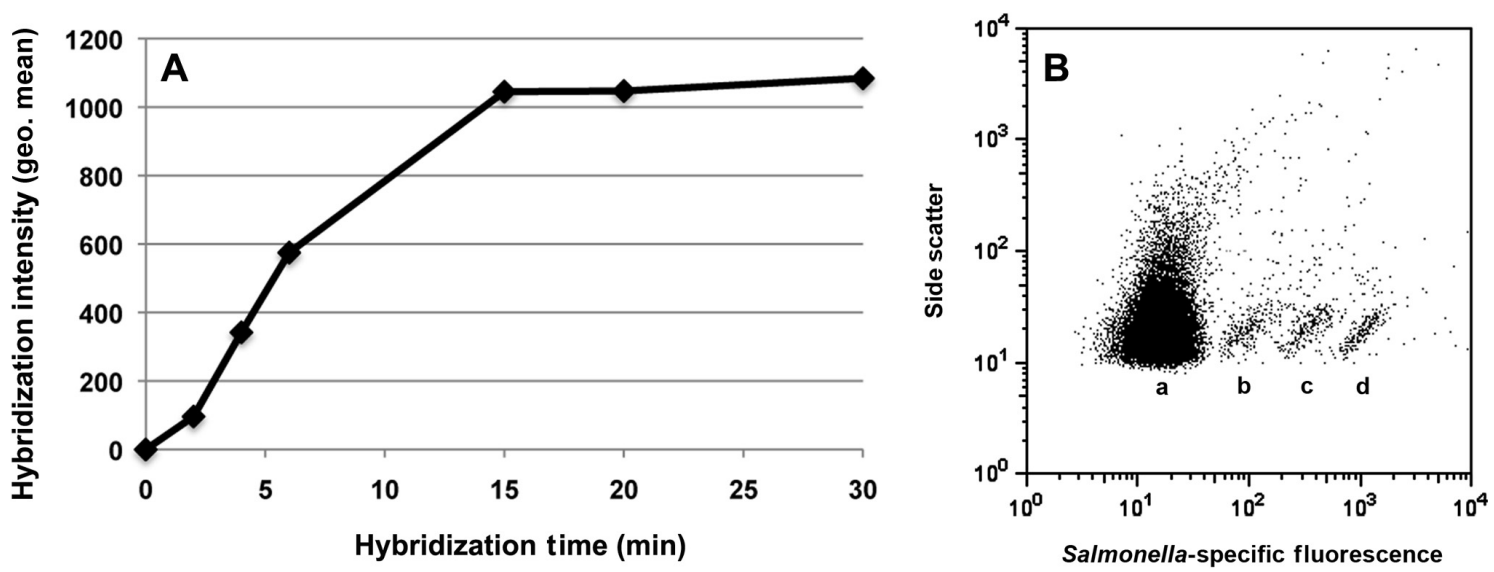

Figure 5. Hybridization signal and separation as a function of time for Salmonella Typhimurium subpopulations in contaminated alfalfa sprouts. Alfalfa sprouts were spiked with $10^{6} \mathrm{CFU} \mathrm{g}{ }^{-1} \mathrm{~S}$. Typhimurium, treated for $30 \mathrm{~min}$ with $5 \times$ Denhardt's solution, fixed for 30 min with $10 \%$ buffered formalin and hybridized using the Sal3/Salm-63 probe cocktail. Panel A: An elliptical gate was drawn around the emerging subpopulation of stained S. Typhimurium cells at each timepoint and the geometric mean signal intensity (GMSI) was calculated. As indicated by the graph, near -maximal staining intensity was achieved after 15 min hybridization. Panel B: Dot plot shows an overlay of data obtained after 2, 4 and $15 \mathrm{~min}$ hybridization for contaminated sprouts $\left(10^{6} \mathrm{CFU} \mathrm{g}^{-1} \mathrm{~S}\right.$. Typhimurium, as above). Nontarget microbiota (subpopulation a) remained unstained at all timepoints. Subpopulations b, $\mathrm{c}$ and $\mathrm{d}$ are $S$. Typhimurium after 2,4 and 15 min hybridization, respectively. Although the signal intensity at $2 \mathrm{~min}$ was only $\sim 8.5 \%$ that of target cells hybridized for 30 min, the Salmonella subpopulation at this timepoint was clearly distinguishable from the non-target background. These data suggest that while maximal staining may require longer hybridization, effective detection of Salmonella may be accomplished at earlier hybridization timepoints. 

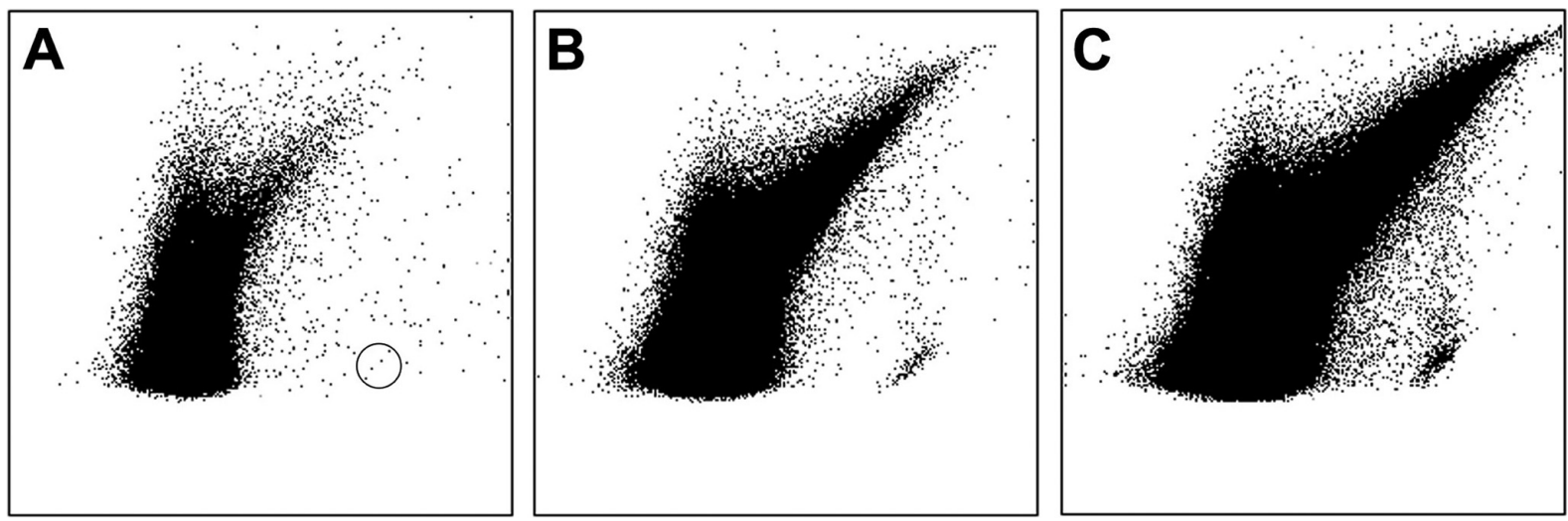

Figure 6. Effects of tangential flow filtration (TFF) on assay sensitivity. Alfalfa sprouts were spiked with $10^{4} \mathrm{CFU} \mathrm{g}^{-1} \mathrm{~S}$. Typhimurium and were homogenized in $0.1 \%$ peptone water as described in Materials and Methods, then either processed directly for FISH and flow cytometry, or first subjected to additional concentration steps via TFF $(\sim 10 x$ concentration) or TFF plus centrifugation $(2,000 \times \mathrm{g}$, $5 \mathrm{~min} ; \sim 100 \mathrm{x}$ concentration). Samples were then fixed with $10 \%$ buffered formalin (without Denhardt's solution), hybridized using the Sal3/Salm-63 DNA probe cocktail and analyzed via flow cytometry. Hybridized samples were analyzed using a high flow rate (120 $\mu$ l $\left.\min ^{-1}\right)$ with a timed collection of 3 minutes ( 360 $\mu$ l total sample analyzed). Panel A: direct analysis of contaminated sprouts, without concentration. The same gating solution was used to calculate event numbers in Salmonella populations for each treatment. Circled area indicates location of a probable Salmonella subpopulation, but the low event number (4 events against a background of 186,829 non-target events) is not sufficient to visually discriminate this population from random noise. Panel B: TFF-concentrated sample; Salmonella subpopulation is visually apparent (117 events against a background of 1,267,990 non-target events). Panel C: TFF concentration + centrifugation; Salmonella subpopulation is again clearly visible (344 events against a background of 4,564,954 non-target events). These data indicate that simple pre-analytical concentration steps can be used to enhance the sensitivity of our cytometric assay for Salmonella in sprouts and may be especially useful when analyzing sprout irrigation water.

\section{DISCUSSION}

Outbreaks of salmonellosis from consumption of contaminated seed sprouts are a chronic/recurring food safety issue. Because sprouts themselves have a very short shelf life, they are typically shipped and consumed locally - within a few hundred miles of the production facility. Therefore, cases of Salmonella contamination due to facility-specific sanitary issues might be expected to be self-limiting, affecting only the relatively small geographical region in which the sprouts were produced. However, the most common source of pathogens in sprout-related disease outbreaks is the seed itself [10, 37], which may be distributed widely, with multistate or even multinational outbreaks possible. Further, implicated seeds may be grown anywhere around the globe and may be composited with seeds from several different farms prior to their sale, distribution and use, complicating outbreak traceback efforts $[5,11]$. Possible modes of seed contamination include contact with animal feces during seed storage (i.e. rodent infestation), agricultural practices such as the use of uncomposted manure or contaminated irrigation water, or direct fecal contamination of crops by migratory birds or other wildlife [5]. Alfalfa is also grown as animal feed and growers should make clear distinctions between crops intended for animal vs. human consumption.

Testing of seeds for pathogens and disinfection of seeds destined for sprouting are two possible approaches when seeking to increase the safety of seed sprouts. Sampling of relatively small amounts of seed (e.g. 25 g or even 500 g) may be performed by a grower or be required of a producer prior to lot acceptance. However, this type of preproduction sampling is not likely to be effective, as such a small sample of seeds may not be truly representative of the production lot, which may consist of thousands of pounds of seeds [15, 37]. Although there have been more reports on antimicrobial interventions for seed sprouts than for any other type of fresh produce [3], none of these has been shown to completely eliminate Salmonella from seeds, especially on an industrial scale $[11,15]$. The random and non-uniform nature of seed contamination, coupled with the inability of seed decontamination steps to remove all pathogens suggest that neither pre-sprouting testing of small seed samples nor seed sanitization can be relied upon as effective control measures for Salmonella in sprouts.

Long standing guidance to producers from the FDA recommends testing of spent sprout irrigation water (SIW) for Salmonella well into the sprouting process as a primary means of intervention [13] and the proposed Food Safety Modernization Act (FSMA) produce rule mandates testing of SIW or the sprouts themselves (Subpart M: Sprouts). Companies have the option of sending samples out for testing by a qualified independent lab, but this is not likely to be a time-effective means for achieving actionable testing results 
[38]. A number of approaches have been developed for more rapid testing of Salmonella in alfalfa or other types of sprouts (e.g. mung bean) and in SIW, including commercially available immunoassay [39] or custom amperometric immunoassay [40], standard PCR [41], automated fiber optic biosensor [42], or automated nucleic acid sensor [38]. Pre-analytical sample preparation is an indispensible element in successful navigation from sample to answer [43]. Sample preparation methods used in conjunction with assays for Salmonella in sprouts include simple centrifugation [41] or filtration [39] and TFF $[40,44]$. Reported levels of sensitivity for detection of Salmonella in SIW were $100 \mathrm{CFU} \mathrm{L}^{-1}\left(0.1 \mathrm{CFU} \mathrm{m}{ }^{-1}\right)$ for standard PCR [41], $300 \mathrm{CFU} \mathrm{ml}^{-1}$ for combined TFF and amperometric immunoassay [40] and $8 \times 10^{5} \mathrm{CFU} \mathrm{ml}^{-1}$ for automated PCR (reported as $10^{4} \mathrm{CFU}$ per $12.5 \mu \mathrm{l}$ sample of SIW) [38]. These are all promising for rapid, and in the case of standard PCR, extremely sensitive detection-based interventions that might be leveraged for increasing the safety of seed sprouts.

However, PCR and immunoassay methods do not directly detect intact cells, but are instead targeted to cellular components that may or may not be associated with living cells, such as DNA or cell surface markers. With the exception of microbial intoxications, it is microbial cells themselves that cause disease, and unlike PCR, whole-cell methods for detection do not require extraction of target molecules prior to their use and also preserve valuable and potentially diagnostic information on cell morphology. For these reasons, whole-cell methods may have distinct advantages over PCR and immunoassay-based approaches for direct identification and possible enumeration of specific target cells in foods.

FISH is a rapid whole-cell approach that enables selective labeling of target cells based on hybridization of fluorescently-labeled, rRNA-targeted oligonucleotide probes [30, 45]. Unlike chemical reagents, FISH is a "smart" (i.e. organism-specific) stain and can be used effectively in highly complex systems such as natural surface waters, activated sludge, feces or soil $[24,46,47,48]$. Combined with an appropriate analytical platform, FISH is a promising tool for whole cell molecular detection of human pathogens in foods or other complex sample matrices [18, 24, 27]. FISH-compatible platforms include fluorescence microscopy and FCM. Because FCM can discriminate on the basis of both probe-conferred fluorescence and light-scatter, it may hold special promise for detection of relatively low levels of selectively-labeled target cells against the high backgrounds of non-target microbiota and particulate matter that are characteristic of certain food matrices, including seed sprouts.

The purpose of the present work was two-fold. First, we sought to develop a simple and streamlined whole cell method for rapid molecular detection of Salmonella in seed sprouts. Second, we sought to assess the capacity of combined FISH and FCM to address the considerable detection challenges posed by the microbiologically and physically complex sprout matrix. For this reason, we sought to test the sprouts themselves, rather than sprout irrigation water, although we believe that our approach will be readily applicable to the testing of SIW, especially when TFF [44] or other methods for cell concentration are used.

The first step in building our assay was an evaluation of four existing 23S rRNA-targeted DNA probes reported in the scientific and patent literature to be specific for Salmonella (Table 1). Two of these have been used individually in work by others, but under substantially different hybridization conditions $\left(0.9 \mathrm{M} \mathrm{NaCl}, 10 \%\right.$ formamide, $46^{\circ} \mathrm{C}$, hybridization times of $1.5 \mathrm{~h}$ or longer) [18]. In contrast, we sought to evaluate the performance of these probes using rapid-labeling (2$30 \mathrm{~min})$, high-temperature FISH conditions [29, 49], and to investigate the potential advantages of probe combinations, which we hypothesized might enable either brighter staining or broader reactivity for Salmonella. All the DNA probes used here were developed independently [19, 20, 21, 22], but we noted upon closer examination that they could be divided into two related pairs of probes, targeting regions on the ribosome corresponding to E. coli rRNA positions in the mid300's (1200 and Sal1) or the mid-1700's (Sal3 and Salm-63). Additionally, we noted that the $1200 /$ Sal1 pair targeted the same region on the ribosome, while the Sal3/Salm-63 pair targeted adjacent ribosomal sites. Because 1200 and Sal1 bind to the same physical site, we did not evaluate them together in a probe cocktail. However, we did evaluate them separately, as they were sufficiently different from one another to merit such testing. Specifically, 1200 is eight bases longer than Sal1 and also contains a single nucleotide substitution at E. coli position 351 that produces a T:G "wobble" effect claimed by the authors to provide greater inclusivity among Salmonella spp. [20]. After establishing baseline hybridization conditions of $30 \mathrm{~min}, 55^{\circ} \mathrm{C}, 5 \mathrm{ng} \mathrm{l}^{-1}$ probe, we determined that hybridizations carried out using $0.7 \mathrm{M} \mathrm{NaCl}$ yielded more uniform staining and fewer stray events.

We also noted apparent cooperative binding behaviors between Sal3 and Salm-63 and confirmed these using a combination of Salm-63-Cy5 and an unlabeled Sal3. This was a fortuitous finding, as it enabled us to use this probe pair to achieve more intense staining of Salmonella than is possible using simply additive combinations of probes [30]. When tested against a panel of Salmonella strains representative of the 7 DNA subgroups of this genus using the new low salt, high temperature/short time conditions, we found that Sal3 and Salm-63 exhibited the same binding profiles as originally reported for these probes and that their inclusivity was additive $[19,21]$. This probe combination can therefore be used to provide both brighter staining and broader coverage for Salmonella spp. The one exception where the Sal3/Salm-63 cocktail did not yield a brighter response was with the strain representative of DNA subgroup IIIa. This result may arise 
from a lack of reactivity for Sal3 with rRNA from this strain. If Sal3 does not react with subgroup III rRNA, it would not be expected to enhance the binding of Salm-63 via cooperative interactions, as seen with the other subgroup strains. However, our success with the helper-probe strategy suggests that we may be able to add to the Sal3/Salm-63 cocktail an unlabeled probe that is fully complementary to the IIIa sequence ("Sal-IIIa": 5'-AAC CGC TTC ACC TAC GTG-3'). We expect that this probe would bind to the rRNA of subroup IIIa strains and modify the localized rRNA accessibility for Salm63 , potentially yielding a more intense signal for strains belonging to this subgroup.

Recently, Almeida and colleagues described a new 23S rRNAtargeted peptide nucleic acid (PNA) probe ("SalPNA1873") targeting Salmonella spp., and demonstrated its use for detection of Salmonella in enrichments from water, powdered infant formula, blood and feces using 30 min hybridizations [24]. While PNA probes sometimes offer tremendous performance advantages over DNA probes (brighter labeling, faster hybridization kinetics, the ability to penetrate thick cell walls or other "difficult" biological structures), our novel use of a cooperatively binding DNA probe cocktail resulted in very bright labeling of Salmonella spp., and near-maximal staining intensity was achieved after only $15 \mathrm{~min}$. Because gram-negative bacteria are relatively easy to permeabilize, the enhanced penetration ability of PNA is not as critical for Salmonella as it may be for other foodborne pathogens, such as Listeria spp. [50]. The excellent performance characteristics and lower expense of our DNA-based approach may therefore provide an economically feasible alternative to the use of PNA for the sprout industry.

The high discriminatory power of FCM, coupled with our DNA-FISH method enabled us to detect relatively low levels of $S$. Typhimurium $\left(10^{4} \mathrm{CFU} \mathrm{\textrm {g } ^ { - 1 }}\right.$ sprouts $/ 10^{3} \mathrm{CFU} \mathrm{\textrm {ml } ^ { - 1 }}$ sprout wash) against very high levels $\left(10^{8} \mathrm{CFU} \mathrm{g}^{-1}\right)$ of physiologically similar or closely-related bacteria and additional particulate matter. Monte Carlo simulations of pathogen behavior during sprouting suggest that probabilities of detecting pathogens in sprout samples are high when methods able to detect $10^{4}$ or fewer cells per gram are used [51] Therefore, we expect that our "FISH and Flow" approach will be valuable for monitoring seed sprouts or sprout irrigation water for Salmonella during production as will be required of producers under FSMA (http://www.fda.gov/downloads/ Food/GuidanceRegulation/FSMA/UCM359285.pdf).

Although FCM can be used to enumerate microbial cells, we found that the high numbers of cells in sprouts and the physical complexity of this food matrix interfered with our ability to do so here. Specifically, we experienced issues with coincidence - instances where at least one labeled $S$. Typhimurium cell passed in front the detector at the same time as did one or more non-target particles (microbial cells or particulates), which we confirmed using flow-through imaging cytometry [27]. While recent improvements in FCM technology such as acoustic focusing FCM [52] could help minimize coincidence in such concentrated samples, the approach described here is limited to presence/absence testing for Salmonella in sprouts.

\section{CONCLUSIONS}

We report the combined use of FISH and FCM for the selective detection of Salmonella spp. in alfalfa sprouts, a complex food system. Factors presenting challenges to detection of Salmonella in this matrix include the presence of high numbers of physiologically and sometimes phylogenetically similar bacteria, as well as fungi and particulate material. Our approach was also successfully applied to related systems, including broccoli and radish sprouts (data not shown), which we showed to be very similar to alfalfa, both physically and microbiologically. Our assay incorporates a novel pairing of DNA probes whose cooperative binding resulted in brighter signals than when individual probes or non-cooperative probe combinations were used. A chemical blocking step (Denhardt's solution) yielded improved results, although we found that this step was not critical to assay performance. Concentration of our samples with TTF and centrifugation enabled us to to reliably detect $S$. Tyhpimurium in alfalfa sprouts at levels as low as $10^{3} \mathrm{CFU} \mathrm{ml}{ }^{-1}$ sprout wash $\left(10^{4}\right.$ $\mathrm{CFU} \mathrm{g}^{-1}$ sprouts). Analysis of larger samples (>360 $\left.\mu \mathrm{l}\right)$ using analysis times greater than $3 \mathrm{~min}$, or use of additional approaches for enhancing hybridization intensity [53] may further improve the sensitivity of our assay. With the recent commercial availability of smaller, task-dedicated and more affordable cytometers, use of this assay may represent a viable approach for enhancing the safety of seed sprouts and complying with strict regulatory standards for sprout production.

\section{ACKNOWLEDGMENTS}

We thank Jean Ross at the University of Iowa's Central Microscopy Research Facility (CMRF, Iowa City, IA) for her expert electron microscopy work. Funding for this work was provided by Iowa State University's Office of Biotechnology and by USDA-NIFA National Integrated Food Safety Initiative Grant No. 2009-51110-05902 "Pathogen inactivation in fresh produce by incorporation of sanitizers into existing operations within the produce chain".

\section{REFERENCES}

[1] Fahey JW, Zhang Y, Talalay P. Broccoli sprouts: an exceptionally rich source of inducers of enzymes that protect against chemical carcinogens. Proc Natl Acad Sci USA. 1997;94:10367-72. doi:10.1073/pnas.94.19.10367

[2] Yanaka A, Fahey JW, Fukumoto A, Nakayama M, Inoue S, Zhang S, Tauchi M, Suzuki H, Hyodo I, Yamamoto M. Dietary sulforaphane-rich broccoli sprouts reduce colonization and attenuate gastritis in Helicobacter pylori-infected mice and humans. Cancer Prev Res. 2009;2:353-60. doi:10.1158/1940-6207. CAPR-08-0192 
[3] Fett WF, Fu T-J, Tortorello ML. Seed sprouts: the state of microbiological safety. In: Mathews KR, editor. Microbiology of fresh produce. Washington (DC): ASM Press; 2006. p. 167-219.

[4] Taormina PJ, Beuchat LR, Slutsker L. Infections associated with eating seed sprouts: an international concern. Emerg Infect Dis. 1999;5:626-34. doi:10.3201/eid0505.990503

[5] Sivapalasingam S, Friedman CR, Cohen L, Tauxe RV. Fresh produce: a growing cause of outbreaks of foodborne illness in the United States, 1973 through 1997. J Food Prot. 2004;67: 2342-53.

[6] Stewart DS, Reineke KF, Ulaszek JM, Tortorello ML. Growth of Salmonella during sprouting of alfalfa seeds associated with salmonellosis outbreaks. J Food Prot. 2001;64:618-22.

[7] Barak JD, Whitehand LC, Charkowski AO. Differences in attachment of Salmonella enterica serovars and Escherichia coli 0157: H7 to alfalfa sprouts. Applied and Environmental Microbiology. 2002;68(10):4758-4763-63. doi:10.1128/AEM.68.10.47584763.2002

[8] Charkowski AO BaBarak JD, SaSarreal CZ, MaMandrell RE. Differences in growth of Salmonella enterica and Escherichia coli 0157:H7 on alfalfa sprouts. Applied and Environmental Microbiology. 2002;68(6):3114-3120-20. doi:10.1128/AEM.68. 6.3114-3120.2002

[9] Emberland KE, Ethelberg S, Kuusi M, Vold L, Jensvoll L, Lindstedt B-A, Nygård K, Kjelsø C, Torpdahl M, Sørensen G, Jensen T, Lukinmaa S, Niskanen T, Kapperud G. Outbreak of Salmonella Weltevreden infections in Norway, Denmark and Finland associated with alfalfa sprouts, July-October 2007. Euro Surveill. 2007;12(11):pii: 3321.

[10] Fu T-J, Reineke KF, Chirtel S, VanPelt OM. Factors influencing the growth of Salmonella during sprouting of naturally contaminated alfalfa seeds. J Food Prot. 2008;71:888-96.

[11] Proctor ME, Hamacher M, Tortorello ML, Archer JR, Davis JP. Multistate outbreak of Salmonella serovar Muenchen infections associated with alfalfa sprouts grown from seeds pretreated with calcium hypochlorite. J Clin Microbiol. 2001;39:3461-5. doi:10.1128/JCM.39.10.3461-3465.2001

[12] Werner S, Boman K, Einemo I, Erntell M, de Jong B, Lindqvist A, Löfdahl M, Lofdahl S, Meeuwisse A, Ohlen G, Olsson M, Stamer U, Sellstrom E, Andersson Y. Outbreak of Salmonella Stanley in Sweden associated with alfalfa sprouts, July-August 2007. Euro Surveill. 2007;12(10):pii: 3291.

[13] U.S. Food and Drug Administration. Guidance for industry: reducing microbial food safety hazards for sprouted seeds and guidance for industry: sampling and microbial testing of spent irrigation water during sprout production. Fed Regist. 1999; 64:57893-902.

[14] Centers for Disease Control and Prevention. Outbreak of Salmonella serotype Saintpaul infections associated with eating alfalfa sprouts - United States, 2009. MMWR Morb Mortal Wkly Rep. 2009;58:1-3.

[15] Montville R, Schaffner DW. Analysis of published sprout seed sanitization studies shows treatments are highly variable. J Food Prot. 2004;67:758-65.

[16] Howard MB, Hutcheson SW. Growth dynamics of Salmonella enterica strains on alfalfa sprouts and in waste seed irrigation water. Appl Environ Microbiol. 2003;69:548-53. doi:10.1128/ AEM.69.1.548-553.2003

[17] Liu B, Schaffner DW. Quantitative analysis of the growth of Salmonella Stanley during alfalfa sprouting and evaluation of Enterobacter aerogenes as its surrogate. J Food Prot. 2007; 70:316-22.

[18] Fang Q, Brockmann S, Botzenhart K, Wiedenmann A. Improved detection of Salmonella spp. in foods by fluorescent in situ hybridization with $23 \mathrm{~S}$ rRNA probes: a comparison with conventional culture methods. J Food Prot. 2002;66: 723-31.

[19] Kutter S, Hartmann A, Schmid M. Colonization of barely (Hordeum vulgare) with Salmonella enterica and Listeria spp. FEMS Microbiol Ecol. 2006;56:262-71. doi:10.1111/j.15746941.2005.00053.x

[20] Nietupski RM, Wilson SG, Shah J, Chan SW, Halbert DN, Lane DJ. Probes and methods for the detection of Salmonella. U.S. Patent 5, 147,778. 1992.

[21] Nordentoft S, Christensen H, Wegener HC. Evaluation of a fluorescence-labelled oligonucleotide probe targeting 23S rRNA for in situ detection of Salmonella serovars in paraffin-embedded tissue sections and their rapid identification in bacterial smears. J Clin Microbiol. 1997;35:2642-8.

[22] Rönner SGE, Stackebrandt E. Development of 23S rRNA oligonucleotide probes for the identification of Salmonella species. Syst Appl Microbiol. 1994;17:257-64.

[23] Alm EW, Oerther DB, Larsen N, Stahl DA, Raskin L. The oligonucleotide probe database. Appl Environ Microbiol. 1996;62: 3557-9.

[24] Almeida C, Azevedo NF, Fernandes RM, Keevil CW, Vieira MJ. A fluorescence in situ hybridization method using a peptide nucleic acid probe for the identification of Salmonella spp. in a broad spectrum of samples. Appl Environ Microbiol. 2010; 76:4476-85. doi:10.1128/AEM.01678-09

[25] Boye K, Høgdall E, BoBorre M. Identification of bacteria using two degenerate $16 \mathrm{~S}$ rDNA sequencing primers. Microbiological Research. 1999;154(1):23-26. doi:10.1016/S0944-5013(99) 80030-5

[26] Diaz MR, Fell JW. High-throughput detection of pathogenic yeasts of the genus Trichosporon. J Clin Microbiol. 2004;42:3696-706. doi:10.1128/JCM.42.8.3696-3706.2004

[27] Bisha B, Brehm-Stecher BF. Flow-through imaging cytometry for characterization of Salmonella subpopulations in alfalfa sprouts, a complex food system. Biotechnol J. 2009;4:880-7. doi:10.1002/biot.200800360

[28] Denhardt DT. A membrane-filter technique for the detection of complementary DNA. Biochem Biophys Res Commun. 1966;23:641-46. doi:10.1016/0006-291X(66)90447-5

[29] Brehm-Stecher BF. Improved methods for the detection and characterization of Listeria and Salmonella. [PhD thesis]. University of Wisconsin-Madison; 2002.

[30] Zwirglmaier K. Fluorescence in situ hybridization (FISH) - the next generation. FEMS Microbiol Lett. 2005;246:151-8. doi:10.1016/j.femsle.2005.04.015

[31] Fuchs BM, Glöckner FO, Wulf J, Amann R. Unlabeled helper oligonucleotides increase the in situ accessibility to $16 \mathrm{~S}$ rRNA of fluorescently labeled oligonucleotide probes. Appl Environ Microbiol. 2000;66:3603-7. doi:10.1128/AEM.66.8.3603-3607. 2000

[32] Fett WF, Cooke PH. A survey of native microbial aggregates on alfalfa, clover and mung sprout cotyledons for thickness as determined by confocal scanning laser microscopy. Food Microbiol. 2005;22:253-9. doi:10.1016/j.fm.2004.03.004

[33] Loui C, Girgoryan G, Huang H, Riley LW, Lu S. Bacterial communities associated with retail alfalfa sprouts. J Food Prot. 2008; 71:200-4.

[34] Mølbak L, Licht TR, Kvist T, Kroer N, Andersen SR. Plasmid transfer from Pseudomonas putida to the indigenous bacteria on alfalfa sprouts: characterization, direct quantification, and in situ location of transconjugant cells. Appl Environ Microbiol. 2003;69:5536-42.

[35] Tournas VH. Moulds and yeasts in fresh and minimally processed vegetables, and sprouts. Int J Food Microbiol. 2005;99: 71-77. doi:10.1016/j.ijfoodmicro.2004.08.009 
[36] Brehm-Stecher B, Tortorello ML. Microscopic methods. In: Tortorello ML, Downes FP, Doores S, Ito K, Salfinger Y, editors. Compendium of methods for the microbiological examination of foods. American Public Health Association; 2013. p. 1-21.

[37] Petit JM. Letter from California Department of Public Health to sprout manufacturers; 2008. Available from http://www.fda. gov/NewsEvents/PublicHealthFocus/ucm152150.htm (accessed May 22, 2010).

[38] Csordas AT, Delwiche MJ, Barak JD. Automatic detection of Salmonella enterica in sprout irrigation water using a nucleic acid sensor. Sens Actuators B Chem. 2008;134:9-17. doi:10.1016/j.snb.2008.05.020

[39] Fu T, Stewart D, Reineke K, Ulaszek J, Schlesser J, Tortorello M. Use of spent irrigation water for microbiological analysis of alfalfa sprouts. J Food Prot. 2001;64:802-6.

[40] McEgan R, Fu TJ, Warriner K. Concentration and detection of Salmonella in mung bean sprout spent irrigation water by use of tangential flow filtration coupled with an amperometric flowthrough enzyme-linked immunosorbent assay. J Food Prot. 2009; 72:591-600.

[41] Johnston LM, Elhanafi D, Drake M, Jaykus L-A. A simple method for the direct detection of Salmonella and Escherichia coli 0157: $\mathrm{H} 7$ from raw alfalfa sprouts and spent irrigation water using PCR. J Food Prot. 2005;68:2256-63.

[42] Kramer MF, Lim DV. A rapid and automated fiber optic-based biosensor assay for the detection of Salmonella in spent irrigation water used in the sprouting of sprout seeds. J Food Prot. 2004;67:46-52.

[43] Brehm-Stecher BF, Young C, Jaykus L-A, Tortorello ML. Sample preparation: the forgotten beginning. J Food Prot. 2009;72: 1774-89.

[44] Fu T-J, Reineke K, Krupinski T, VanPelt O, Maks-Warren N, Parisi B, Slade P. Integrating tangential flow filtration with rapid tests for detection of E. coli 0157:H7, Salmonella and L. monocytogenes in large volumes of spent sprout irrigation water. IAFP Annual Meeting, 13 to 17 August 2005, Baltimore, MD; 2005.

[45] Moter A, Göbel UB. Fluorescence in situ hybridization (FISH) for direct visualization of microorganisms. J Microbiol Methods. 2000;41:85-112. doi:10.1016/S0167-7012(00)00152-4

[46] Bertaux J, Gloger U, Schmid M, Hartmann A, Scheu S. Routine fluorescence in situ hybridization in soil. J Microbiol Methods. 2007;69:451-60. doi:10.1016/j.mimet.2007.02.012

[47] Lenaerts J, Lappin-Scott HM, Porter J. Improved fluorescent in situ hybridization method for detection of bacteria from activated sludge and river water by using DNA molecular beacons and flow cytometry. Appl Environ Microbiol. 2007;73:2020-3. doi:10.1128/AEM.01718-06

[48] Rochet V, Rigottier-Gois L, Rabot S, Doré J. Validation of fluorescent in situ hybridzation combined with flow cytometry for assessing interindividual variation in the composition of human fecal microflora during long-term storage of samples.
J Microbiol Methods. 2004;59:263-70. doi:10.1016/j.mimet. 2004.07.012

[49] Tang YZ, Gin KYH, Lim TH. High-temperature fluorescent in situ hybridization for detecting Escherichia coli in seawater samples, using rRNA-targeted oligonucleotide probes and flow cytometry. Appl Environ Microbiol. 2005;71:8157-64. doi:10.1128/ AEM.71.12.8157-8164.2005

[50] Brehm-Stecher BF, Hyldig-Nielsen JJ, JoJohnson EA. Design and Evaluation of $16 \mathrm{~S}$ rRNA-Targeted Peptide Nucleic Acid Probes for Whole-Cell Detection of Members of the Genus Listeria. Applied and Environmental Microbiology. 2005;71(9):54515457. doi:10.1128/AEM.71.9.5451-5457.2005

[51] Montville R, Schaffner D. Monte Carlo simulation of pathogen behavior during the sprout production process. Appl Environ Microbiol. 2005;71:546-753. doi:10.1128/AEM.71.2.746-753. 2005

[52] Goddard G, Martin JC, Graves SW, Kaduchak G. Ultrasonic particle-concentration for sheathless focusing of particles for analysis in a flow cytometer. Cytometry A. 2006;69A:66-74. doi:10.1002/cyto.a.20205

[53] Stoecker K, Dorninger C, Daims H, Wagner M. Double labeling of oligonucleotide probes for fluorescence in situ hybridization (DOPE-FISH) improves signal intensity and increases rRNA accessibility. Appl Environ Microbiol. 2010;76:922-6. doi:10. 1128/AEM.02456-09

\section{COMPETING INTERESTS}

The authors declare no competing interests.

\section{PUBLISHING NOTES}

(C) 2014 B. Bisha and B.F. Brehm-Stecher. This work has been published open access under Creative Commons Attribution License CC BY 4.0, which permits unrestricted use, distribution, and reproduction in any medium, provided the original work is properly cited. Conditions, terms of use and publishing policy can be found at www.scienceopen.com.

Please note that this article may not have been peer reviewed yet and is under continuous post-publication peer review. For the current reviewing status please click here or scan the QR code on the right.

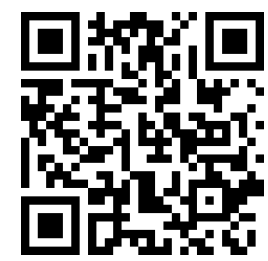

\section{scienceOPEN.com}

